\title{
Rendimento de coentro (Coriandrum sativum L. ) em sistema de adubação verde com a planta jitirana (Merremia aegyptia L. )
}

\author{
LINHARES, P.C.F*.; PEREIRA, M.F.S.; DIAS, M.A.V.; HOLANDA, A.K.B.; MOREIRA, J.C. \\ Universidade Federal Rural do Semi-Árido,Departamento de Fitotecnia, Campus Mossoró, Av. Francisco Mota, \\ Caixa Postal 137, CEP: 59625-900, Mossoró-Brasil *paulojitirana@yahoo.com.br
}

\begin{abstract}
RESUMO: O coentro é a hortaliça mais utilizada como condimento na região de Mossoró-RN. Um experimento foi conduzido na Fazenda Experimental Rafael Fernandes da Universidade Federal Rural do Semi-Árido - UFERSA, no período de maio a junho de 2010, com o objetivo de avaliar o rendimento de coentro sob diferentes quantidades da planta trepadeira jitirana, incorporada ao solo como adubo verde. O delineamento experimental usado foi o de blocos completos casualizados com sete tratamentos e três repetições. Os tratamentos consistiram da incorporação de sete quantidades de jitirana $\left(3,0 ; 6,0 ; 9,0 ; 12,0 ; 15,0 ; 18,0\right.$ e $21,0 \mathrm{t} \mathrm{ha}^{-1}$ de matéria seca de jitirana). A cultivar de coentro plantado foi a Verdão. As características avaliadas foram: altura e número de hastes por planta, rendimento e massa seca da parte aérea. O melhor desempenho agronômico do coentro foi observado na quantidade de $21,0 \mathrm{t} \mathrm{ha}^{-1}$ de jitirana. Para cada tonelada de jitirana incorporada ao solo observa-se um rendimento de coentro de $395 \mathrm{~kg} \mathrm{ha}^{-1}$.
\end{abstract}

Palavras-chave: planta condimentar, Coriandrum sativum L., Merremia aegyptia L.

ABSTRACT: Yield of coriander (Coriandrum sativum L.) in a system of green manure with the plant scarlet starglory (Merremia aegyptia L.). The ciliandro is the vegetable more used as seasoning in the area at Mossoró-RN. An experiment was conducted at the Experimental Farm Rafael Fernandes of the Universidade Federal Rural do Semi-Árido - UFERSA in the period from may to june 2010, with the objective of evaluating the coriander yield in under different amounts of plant clambering scarlet starglory, incorporated into the soil. The experimental design was randomized complete blocks with eight treatments and three replicates. The treatments were combinations of eight amounts of scarlet starglory $\left(3.0 ; 6.0 ; 9.0 ; 12.0 ; 15.0 ; 18.0\right.$ and $21.0 \mathrm{tha}^{-1}$ dry matter). The coriander cultivar planted was Verdão. The characteristics evaluated in the coriander were: plant height and number of stalks per plant, yield and dry matter mass of shoots. The best agroconomic performance lettuce was observed in the amount of $21,0 \mathrm{t} \mathrm{ha}^{-1}$ scarlet starglory. For each fresh or dry scarlet starglory ton incorporated into the soil, it was observed a mean yield of coriander mass of $395 \mathrm{~kg} \mathrm{ha}^{-1}$.

Key words: condiment plant, Coriandrum sativum L., Merremia aegyptia L.

\section{INTRODUÇÃO}

O coentro (Coriandrum sativum L.) é uma espécie vegetal pertencente à família Apiaceae; herbácea, anual, originária da região mediterrânea (Costa, 2002). No Brasil, as folhas são amplamente utilizadas como tempero na culinária, especialmente na região nordeste (Melo et al., 2003). As sementes são bastante utilizadas na indústria como condimento para carne defumada e na fabricação de pães, picles e licores finos (Filgueira, 2003). A cultura se adapta bem a regiões de clima quente e intolerante a baixas temperaturas, apresenta precocidade no ciclo (45 a 60 dias), o que garante retorno rápido do capital investido, aumentando a renda das famílias envolvidas na exploração, tornando-se então, uma espécie de notável alcance social (Filgueira, 2003).

Na região de Mossoró-RN, os plantios são efetuados em hortas domésticas, no sistema de agricultura familiar, e tendo como fonte de adubo, esterco (bovino e caprino). Desta forma, a dependência desses insumos torna o produtor vulnerável, à escassez, pois nem sempre o mesmo dispõe desse recurso na propriedade, o que aumenta os custos de produção.

Uma das alternativas para viabilizar esses sistemas de produção é a adubação verde, uma vez que seu emprego na produção de hortaliças pode

Recebido para publicação: setembro de 2011

Aceito para publicação: março de 2012

Rev. Bras. PI. Med., Botucatu, v.14, n.esp., p.143-148, 2012. 
representar contribuições consideráveis no que se refere à redução de gastos, contribuindo para a viabilidade econômica e sustentabilidade dos agroecossistemas, pelo aporte de quantidades expressivas de $\mathrm{N}$ ao sistema solo-planta, reduzindo assim, a necessidade de $\mathrm{N}$ industrial (Perin et al., 2004). Segundo Favero et al. (2000), as espécies mais utilizadas nesses sistemas de produção são as leguminosas, pelo fato destas terem a capacidade de fixar nitrogênio por simbiose de bactérias em seus sistemas radiculares. No entanto, o mesmo autor afirma que as especies espontâneas podem contribuir para o aumento da matéria orgânica do solo em relação as especies introduzidas.

Nesse contexto, a jitirana (Merremia aegyptia L.), espécie espontânea do bioma caatinga, é uma liana (hábito trepador), anual, herbácea, da família Convolvulaceae, com produção média de fitomassa verde e seca da ordem de 36000 e $4000 \mathrm{~kg} \mathrm{ha}^{-1}$, respectivamente, com teor de nitrogênio de $26,2 \mathrm{~g}$ $\mathrm{kg}^{-1}$ na matéria seca (Linhares et al., 2008), possui relação C/N de 18/1, o que viabiliza a espécie para uso como adubo verde pela rápida decomposição da palhada.

Nesse sentido, um importante aspecto a ser considerado quando se estuda a produção orgânica de hortaliças, como o coentro, de notável alcance social, é a utilização de adubos verdes, principalmente de espécie presente nas áreas de cultivo, o que garante uma opção a mais para o produtor como adubo orgânico no sistema de produção. Assim sendo, objetivou-se avaliar diferentes quantidades de jitirana como adubo verde na produtividade de coentro.

\section{MATERIAL E MÉTODO}

O experimento foi conduzido na Fazenda Experimental Rafael Fernandes, localizada no distrito de Alagoinha, zona rural de Mossoró-RN, no período de maio a junho de 2010 , em solo classificado como Latossolo Vermelho Amarelo Argissólico franco arenoso (EMBRAPA, 2006). O distrito de Alagoinha está situado nas seguintes coordenadas: latitude $5^{\circ} 03^{\prime} 37^{\prime \prime S}$ e longitude de $37^{\circ} 23^{\prime} 50^{\prime \prime} \mathrm{W} \mathrm{Gr}$, com altitude de aproximada de $72 \mathrm{~m}$, distando $20 \mathrm{~km}$ da cidade de Mossoró-RN. Segundo Thornthwaite, o clima local é DdAa', ou seja, semi-árido, megatérmico e com pequeno ou nenhum excesso d'água durante o ano, e de acordo com Köppen é BSwh', seco e muito quente, com duas estações climáticas: uma seca, que geralmente compreende o período de junho a janeiro e uma chuvosa, entre os meses de fevereiro e maio (Carmo filho et al., 1991).

Antes da instalação do experimento foram retiradas amostras de solo na profundidade de 0-20 $\mathrm{cm}$, as quais foram secas ao ar e peneirada em malha de $2 \mathrm{~mm}$, em seguida foram analisadas no Laboratório de Química e Fertilidade de Solos da UFERSA, cujos resultados foram os seguintes: $\mathrm{pH}$ (água 1:2,5) $=6,0$; $\mathrm{Ca}=2,0 \mathrm{cmol}_{\mathrm{c}} \mathrm{dm}^{-3} ; \mathrm{Mg}=0,5 \mathrm{cmol}_{\mathrm{c}} \mathrm{dm}^{-3} ; \mathrm{K}=0,12$ $\mathrm{cmol}_{\mathrm{C}} \mathrm{dm}^{-3} ; \mathrm{Na}=0,20 \mathrm{cmol}_{\mathrm{c}} \mathrm{dm}^{-3} ; \mathrm{P}=27,7 \mathrm{mg} \mathrm{dm}^{-3} \mathrm{e}$ M.O. $=0,36 \%$.

O delineamento foi em blocos completos casualizados com sete tratamentos e três repetições. Os tratamentos foram constituídos da combinação de sete quantidades de jitirana seca incorporadas ao solo $\left(3,0 ; 6,0 ; 9,0 ; 12,0 ; 15,0 ; 18,0\right.$ e $21,0 \mathrm{t} \mathrm{ha}^{-1}$ de matéria seca).

Cada parcela constou de seis fileiras de plantas espaçadas de 0,2 $\mathrm{m} \times 0,05 \mathrm{~m}$ com duas plantas por cova, totalizando quarenta e oito plantas por fileira, sendo as linhas laterais consideradas bordaduras. A área total da parcela de $1,44 \mathrm{~m}^{2} \mathrm{e}$ a área útil de $0,8 \mathrm{~m}^{2}$, contendo cento e sessenta plantas.

A jitirana utilizada no experimento foi colhida em área da UFERSA nos meses de maio e junho de 2009 , triturada em máquina forrageira convencional, obtendo-se partículas entre 2,0 e $3,0 \mathrm{~cm}$, acondicionadas em sacos de ráfia com teor de umidade médio de $10 \%$ e armazenada nas instalações da UFERSA em ambiente seco adequado para a conservação de material fenado. Por ocasião da instalação do experimento foram retiradas cinco amostras de jitirana seca, levadas para o Laboratório de Análise Vegetal do Departamento de Solos da UFERSA para as análises de nitrogênio, fósforo, potássio e relação carbono nitrogênio, cuja concentração química foi de 25,6; 11,0 e 10,0 g kg-1 e 18/1, respectivamente. Quantificados e incorporados na camada de $0-20 \mathrm{~cm}$ do solo nas parcelas experimentais referente aos tratamentos acima citados. A jitirana ficou em processo de decomposição por um período de trinta dias antes do plantio do centro. Durante esse período fizeram-se irrigações com a finalidade de manter a umidade do solo entre $70 \%$ da capacidade de campo, sendo essa, uma condição ideal para o processo de nitrificação (Meurer et al., 2007).

A variedade de coentro utilizada foi a "Super verdão", utilizada na região durante o período chuvoso, plantada em semeadura direta, colocando-se seis sementes por cova. Dez dias após a emergência (DAE), foi realizado o desbaste das parcelas, deixando-se duas plantas por cova, perfazendo uma população de 2.000 .000 de plantas ha-1. Durante a condução do experimento foram efetuadas regas diárias, para permanência da umidade no solo, e capinas manuais, para o controle da competição entre as plantas.

Aos trinta e cinco dias após a semeadura (DAS) realizou-se a colheita do experimento. Foram realizadas avaliações das características: altura de planta $\left(\mathrm{cm} \mathrm{planta}^{-1}\right)$, número de hastes por planta

Rev. Bras. PI. Med., Botucatu, v.14, n.esp., p.143-148, 2012. 
(termos de média por planta), rendimento e massa da matéria seca de coentro $\left(\mathrm{kg} \mathrm{ha}^{-1}\right)$. A altura de planta foi tomada de amostra de vinte plantas medindo a altura da base até o ápice da planta utilizando régua milimetrada. Para a determinação do número de hastes foi tomada de amostra de vinte plantas e contada o número de hastes expresso em termos de média. Na avaliação do rendimento de coentro utilizouse o índice de $70 \%$ de área total, já que os espaços entre os canteiros não são cultivados (condição regional). Assim, considerou-se como rendimento, o resultado do produto entre o peso por $\mathrm{m}^{2}$ de canteiro e a área de um hectare. O rendimento foi obtido pela pesagem da parte aérea (em balança eletrônica com precisão para $1,0 \mathrm{~g}$ ) logo após o corte realizado acima do colo da planta. A massa seca foi obtida em estufa de aquecimento com ar forçado a $65^{\circ} \mathrm{C}$, até massa constante.

Uma análise univariada de variância para delineamento de blocos casualizados foi realizada em cada característica do coentro, através do aplicativo software ESTAT (Kronka \& Banzato, 1995). O procedimento de ajustamento de curva de resposta foi realizado através do software Table Curve (Jandel Scientific, 1991). As funções respostas foram avaliadas com base nos seguintes critérios: lógica biológica, significância do quadrado médio do resíduo da regressão ( $Q M R r)$, alto valor do coeficiente de determinação $\left(R^{2}\right)$, significância dos parâmetros da regressão, utilizando-se o teste t ao nível de $5 \%$ de probabilidade.

\section{RESULTADO E DISCUSSÃO}

Observou-se efeito significativo para todas as características avaliadas em função das diferentes quantidades de jitirana incorporado no solo (Tabela 1).

Um comportamento crescente na altura de planta de coentro foi observado em função das quantidades de jitirana incorporadas ao solo, onde a altura máxima de $16,1 \mathrm{~cm}$ foi alcançada na quantidade de $21 \mathrm{t} \mathrm{ha}^{-1}$. O acréscimo entre a menor $\left(3 \mathrm{t} \mathrm{ha}^{-1}\right)$ e a maior (21 tha-1) quantidade de jitirana, foi da ordem de $6,8 \mathrm{~cm}_{\text {planta-1 }}$ (Figura 1). Resultados superiores foram encontrados por Tavella et al. (2010), estudando o cultivo orgânico de coentro em plantio direto utilizando cobertura viva e morta, adubado com composto, encontraram altura máxima de coentro de $24,34 \mathrm{~cm}_{\text {planta }}{ }^{-1}$, no sistema de plantio utilizando amendoim forrageiro como planta adubadeira. Essa diferença em relação ao trabalhado em estudo, está no fato do autor ter utilizado uma combinação de fontes de adubo (composto mais cobertura morta) o que contribuiu para o aumento em altura. A baixa estatura das plantas de coentro, possivelmente pode estar relacionada ao fato de que em condições de altas densidades populacionais de plantas, como a verificada nesse experimento (2.000.000 de plantas ha $^{-1}$ ), ocorre uma competição por elementos de alta mobilidade no solo, como é o caso do nitrogênio, responsável pela expansão foliar, ou seja, estatura da planta e indispensável para o processo da fotossíntese, assim como o fósforo, que contribui para o desenvolvimento do sistema do radicular, ocasionando maior crescimento na planta (Meurer et al., 2007).

Para o número de haste foi observado um comportamento crescente em função das quantidades de jitirana incorporadas ao solo, onde o maior número de haste $\left(11,0\right.$ planta $\left.^{-1}\right)$ foi obtido na quantidade de jitirana de $21 \mathrm{t} \mathrm{ha}^{-1}$ (Figura 2). Valores estes superiores ao encontrado por Jales et al. (2006) estudando o desenvolvimento do coentro cultivado com húmus de minhoca que obteve 5,10 hastes por plantas. Assim como, Cavalcante Neto et al. (2010) estudando o cultivo do coentro com e sem cobertura com raspa de madeira, com 8,4 hastes planta-1 no tratamento com raspa de madeira sendo inferior ao presente estudo. No entanto, esses valores distaram dos encontrados por Resende et al. (2008) estudando o desempenho

TABELA 1. Valores de F para altura de planta (AT), número de hastes por planta (NH), rendimento (RC) e massa da matéria seca (MMSC) de coentro (Coriandrum sativum L). Mossoró, UFERSA, 2011.

\begin{tabular}{lccccc}
\hline Causas de Variação & GL & AT & NH & RC & MMSC \\
\hline Tratamentos & 6 & $90,19^{*}$ & $325,33^{*}$ & $283,70^{*}$ & $226,35^{*}$ \\
Blocos & 2 & $1,18^{n . s}$ & $1,95^{n . s}$ & $0,43^{n . s}$ & $0,87^{*}$ \\
\hline Resíduo & 12 & - & - & & - \\
\hline CV $(\%)$ & - & 1,78 & 1,66 & 12,33 & 3,61 \\
\hline Média Geral & - & 12,6 & 8,6 & 6235 & 450,0 \\
\hline
\end{tabular}

${ }^{* *}=P<0,01 ;{ }^{*}=P<0,05 ;$ ns $=P>0,05$

Rev. Bras. PI. Med., Botucatu, v.14, especial, p.143-148, 2012. 


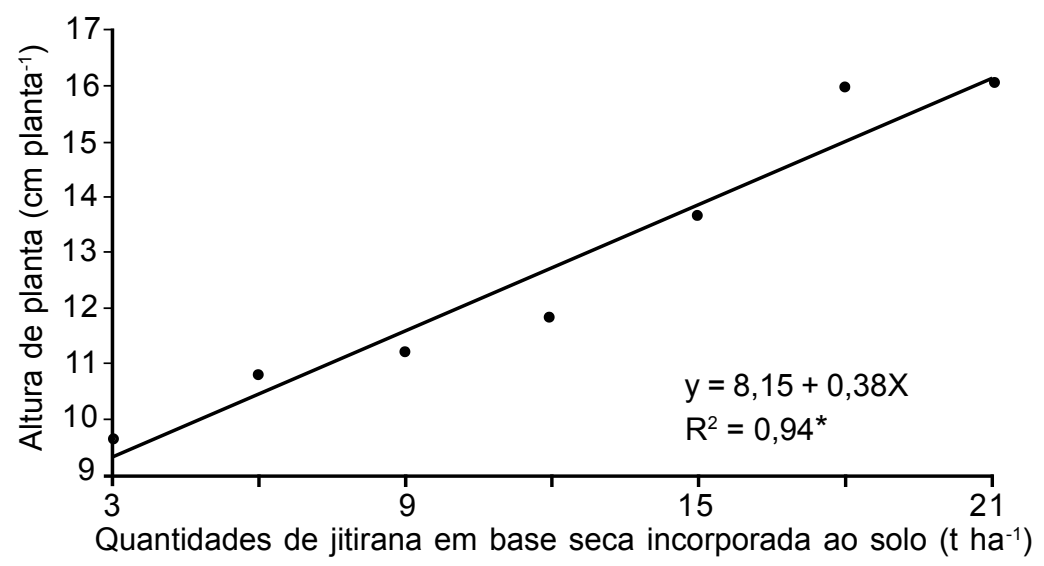

FIGURA 1. Altura de planta de coentro (Coriandrum sativum L.) em função de diferentes quantidades de jitirana (Merremia aegyptia L.) em base seca incorporada ao solo.

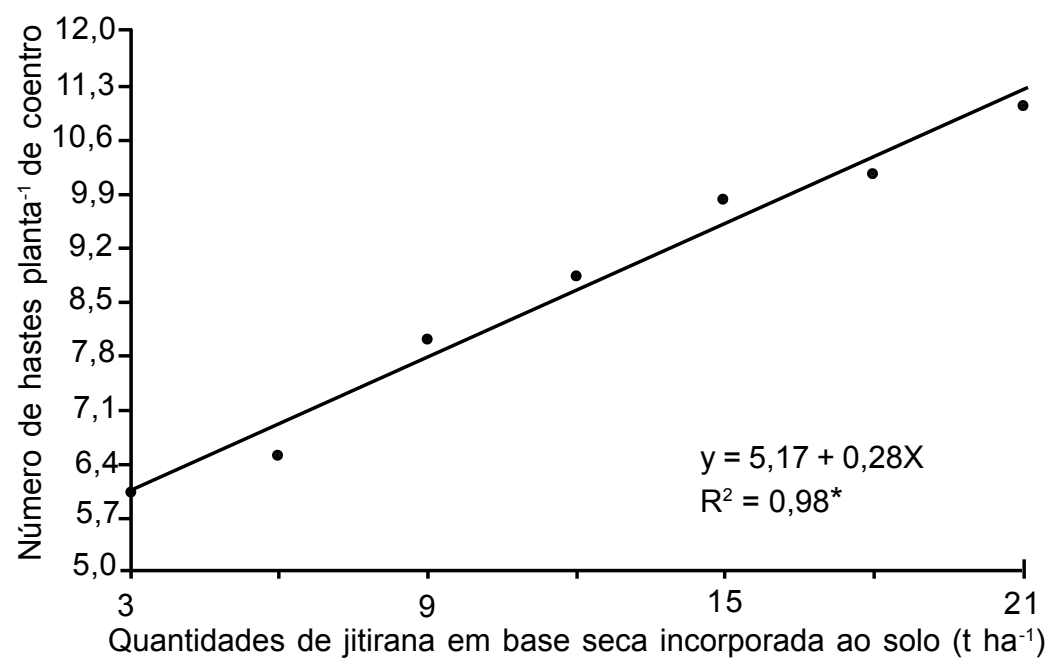

FIGURA 2. Número de hastes por planta de coentro (Coriandrum sativum L.) em função de diferentes quantidades de jitirana (Merremia aegyptia L.) em base seca incorporada ao solo.

fitotécnico do consorcio couve $x$ coentro e o efeito na abundância de joaninhas em sistema de cultivo orgânico com número médio de hastes planta $^{-1}$ de 13,3 .

À medida que aumentou a quantidade de jitirana, um aumento foi observado tanto no rendimento como na massa da matéria seca da parte aérea do coentro até a quantidade máxima utilizada de $21 \mathrm{t} \mathrm{ha}^{-1}$, com valores de $8305 \mathrm{~kg}$ $\mathrm{ha}^{-1}$ e $1284 \mathrm{~kg} \mathrm{ha}^{-1}$ respectivamente (Figuras $3 \mathrm{e}$ 4), correspondendo a um acréscimo de $106 \%$ no rendimento em relação a menor quantidade $\left(3,0 \mathrm{t} \mathrm{ha}^{-1}\right)$. O incremento no rendimento foi de $395 \mathrm{~kg}$ para cada tonelada de jitirana incorporada ao solo. Tavella et al. (2010), estudando o cultivo orgânico de coentro em plantio direto utilizando cobertura viva e morta adubado com composto, encontraram produtividade de $3454,3 \mathrm{~kg} \mathrm{ha}^{-1}$, no sistema de plantio com plantas espontânea, inferior ao referido trabalho. Assim como, com resteva morta, o mesmo autor obteve produtividade de $8000 \mathrm{~kg} \mathrm{ha}^{-1}$.

Este resultado se deve possivelmente a maior disponibilidade de nutrientes no solo, com o momento de maior exigência da cultura, tendo em vista que o coentro foi semeado trinta dias após a incorporação da jitirana, atendendo o momento de maior disponibilidade de nutrientes para a cultura. A eficácia da adubação verde está condicionada à escolha adequada do adubo a ser utilizado, tendo como importância os fatores climáticos, o solo, o sistema agrícola adotado e a finalidade da adubação. Um fator importante na eficiência dessa técnica, é que deve haver sincronia entre os 


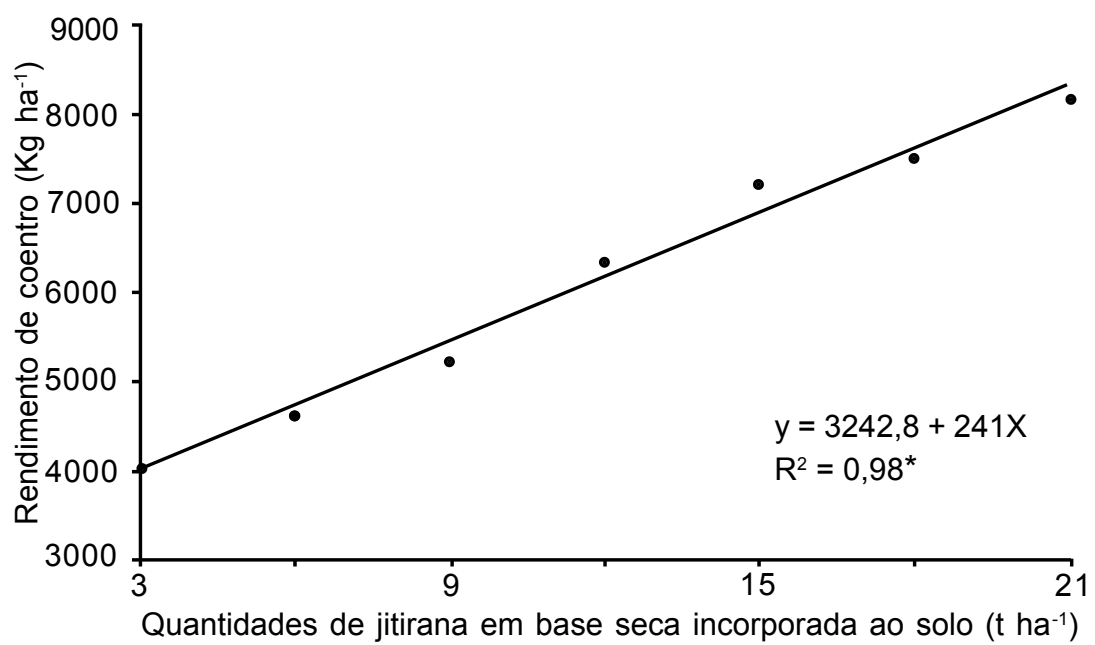

FIGURA 3. Rendimento de coentro (Coriandrum sativum L.) em função de diferentes quantidades de jitirana (Merremia aegyptia L.) em base seca incorporada ao solo.

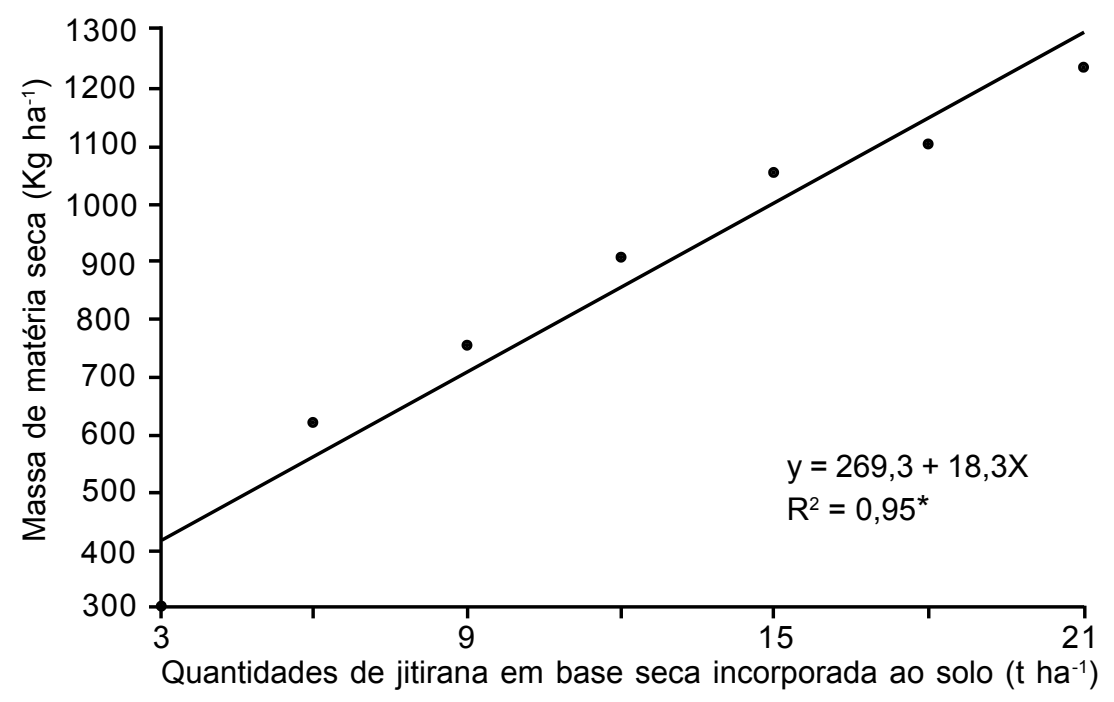

FIGURA 4. Massa da matéria seca de coentro (Coriandrum sativum L.) em função de diferentes quantidades de jitirana (Merremia aegyptia L.) em base seca incorporada ao solo.

nutrientes liberados pelos resíduos vegetais e a demanda da cultura de interesse comercial. Se houver alta taxa de mineralização dos nutrientes, contida nas espécies utilizadas como adubo verde fora do período de maior demanda nutricional da cultura de interesse econômico, pode haver perdas por lixiviação e a cultura não será beneficiada (Crews \& Peoples, 2005).

Conclui-se que o melhor desempenho agronômico do coentro foi observado na quantidade de 21,0 t ha-1 de jitirana. Sendo que, para cada tonelada de jitirana incorporada ao solo observou-se um rendimento de coentro de $395 \mathrm{~kg} \mathrm{ha}^{-1}$.

\section{AGRADECIMENTO}

Ao Grupo de Pesquisa Jitirana e à UFERSA Mossoró/RN, por oferecerem aparato físico para o desenvolvimento dos trabalhos.

\section{REFERÊNCIA}

CARMO FILHO, F.; ESPÍNOLASOBRINHO, J.; MAIANETO, J.M. Dados climatológicos de Mossoró. 1.ed. Mossoró: Coleção mossoroense, 1991. 121p.

CREWS, T.E.; PEOPLES, M.B. Can the synchrony of nitrogen supply and crop demand be improved in legume and fertilizer-based Agroecosystems? A review. Nutrient Cycling in Agroecosystems, v.72, p.101-20, 2005.

COSTA, A.F. Farmacognosia. 6.ed. Lisboa: Fundation 
Calouste Gulbenkian, 2002. 1031p.

CAVALCANTE NETO, J.G. et al. Cultivo do coentro com e sem cobertura do solo em diferentes espaçamentos. Revista Engenharia Ambiental, v.7, n.4, p.106-12, 2010. EMPRESABRASILEIRADE PESQUISAAGROPECUÁRIAEMBRAPA. Sistema brasileiro de classificação de solos. 2.ed. Rio de Janeiro: Embrapa, 2006. 306p.

FAVERO, C. et al. Crescimento e acúmulo de nutrientes por plantas espontâneas e por leguminosas utilizadas para adubação verde. Revista Brasileira de Ciência do Solo, v.24, p.171-7, 2000.

FILGUEIRA, F.A.R. et al. Novo manual de olericultura: Viçosa: UFV, 2003. p.289-90.

JALES, F.E.B. et al. Estudo do desenvolvimento do coentro (cv verdão) cultivado com o húmus de minhoca vermelha da Califórnia. Revista Verde de Agroecologia e Desenvolvimento Sustentável, v.1, n.2, p.34-40, 2006. JANDELSCIENTIFIC. Table curve: curve fitting software. Corte Madera, CA: Jandel Scientific, 1991. 280p.

KRONKA, S.N.; BANZATO, D.A. ESTAT: sistema para análise estatística versão 2. 3.ed. Jaboticabal: Funep, 1995. 243p.
LINHARES, P.C.F. et al. Produção de fitomassa e teores de macronutrientes da jitirana em diferentes estágios fenológicos. Revista Caatinga, v.21, n.4, p.72-8, 2008. MELO, E.A. et al. Antioxidant activity of coriander extracts (Coriandrum sativum L.). Ciência e Tecnologia de Alimentos, v.23, p.195-9, 2003.

MEURER, E.J. Fatores que influenciam o crescimento e o desenvolvimento das plantas. In: NOVAIS, R.F. et al. Fertilidade do solo. Viçosa: Sociedade Brasileira de Ciência do Solo, 2007. p.65-90.

PERIN, A. et al. Efeito residual da adubação verde no rendimento do brócolo (Brassica oleracea L. var. Italica) cultivado em sucessão ao milho (Zea mays L.). Ciência Rural, v.34, p.1739-45, 2004.

RESENDE et al. Desempenho fitotécnico do consorcio couve $x$ coentro e seu efeito na abundância de joaninhas em sistema de cultivo orgânico. Seropédica: Embrapa Agrobiologia, 2008. p.1-6, (Circular Técnica, 26).

TAVELLA, L.B. et al. Cultivo orgânico de coentro em plantio direto utilizando cobertura viva e morta adubado com composto. Revista Ciência Agronômica, v.41, n.4, p. 6148, 2010. 